\title{
Analysis of the actions of NPP personnel in making decisions
}

\author{
M.A. Berberova ${ }^{1}$, A.Kh.Khakimova ${ }^{2}$, O.V.Zolotarev ${ }^{3}$ \\ maria.berberova@gmail.com | aida khatif@mail.ru | ol-zolot@yandex.ru \\ ${ }^{1}$ MIREA - Russian Technological University, Moscow, Russia \\ ${ }^{2} \mathrm{ANO}$ «Scientific and Research Center for Information in Physics and Technique», Nizhny Novgorod, Russia \\ ${ }^{3}$ ANO «Russian New University», Moscow, Russia
}

\begin{abstract}
The operational experience of nuclear facilities shows that personnel reliability has a significant impact on safety. We consider the reliability of the staff as the property (ability) of the staff to accurately and timely perform the necessary actions prescribed by the operating instructions, both during normal operation and in an accident. Personnel Reliability Analysis (PRA) is one of the significant tasks of probabilistic safety analysis. There are problem situations at NPP: the analysis methods and techniques used, the variety of solving tasks, the wide range and diverse nature of errors that a human operator can potentially make, the numerous factors affecting the probability of a particular error. All this makes it necessary to develop an automated personnel reliability analysis system that can support a specialist performing probabilistic safety analysis (PSA) in terms of performing the reliability analysis of the human operator, to ensure the required accuracy, quality and completeness of the results of the personnel reliability analysis.
\end{abstract}

Key words: personnel, the most dangerous accidents, personnel reliability, stress, normal operation, emergency.

\section{Introduction}

The current practice of performing personnel reliability analysis during PSA involves the use of a number of methods of qualitative and quantitative PRAs, as part of a structured procedure for their application. PRA contains numerous levels and stages. In particular, the formation of a list of personnel actions, a selection analysis and a detailed analysis of the most significant actions of the personnel, the determination of the probabilities of an error in the performance of actions, the analysis of the relationships between the actions of the personnel, the analysis of the possibilities to correct the mistake made, and the assessment of the uncertainty of the personnel reliability indicators. The reliability of the human operator depends on a combination of factors, and the most important for analysis used to be the available time, stress level, and staff qualification level.

Currently, the application of these methods to perform various stages of the PRA requires manual processing by the executor of large amounts of information presented in the form of tables and graphs, which increases the analysis timeline and reduces the quality of its implementation.

\section{Decision making by the NPP operator}

The operator's activity consists of a set of sequential actions to develop a solution and implement management.

The development of a solution is a process that consists of three stages [1]:

1. Information search (perception of information) (table 1).

2. Information preparation of decision making (table 2).

3. Decision making (table 3).

Table 1. Information search

\begin{tabular}{|c|c|c|}
\hline Actions & Operations & The inclusion of psychological processes \\
\hline Signal Detection & $\begin{array}{c}\text { Search eye movement, signal extraction from the } \\
\text { background }\end{array}$ & Attention, signal and background perception \\
\hline Comparison with the standard & Feature Comparison & Visual thinking, random access memory \\
\hline Identification & $\begin{array}{c}\text { Identification of similarities and differences, } \\
\text { identification of essential features, categorization, } \\
\text { memorization }\end{array}$ & Operational thinking, long-term memory \\
\hline
\end{tabular}

Table 2. Information preparation for decision making

\begin{tabular}{|c|c|c|}
\hline \multicolumn{1}{|c|}{ Tabtions } & Operations & The inclusion of psychological processes \\
\hline $\begin{array}{c}\text { Information processing about the problematic } \\
\text { situation }\end{array}$ & $\begin{array}{c}\text { The operation of constructing a figurative- } \\
\text { conceptual model (FCM) of the situation }\end{array}$ & Visual action, visual thinking \\
\hline $\begin{array}{c}\text { Search for essential information. Highlighting } \\
\text { from background information. Situation } \\
\text { classification }\end{array}$ & $\begin{array}{c}\text { Image conversion operations, comparisons, } \\
\text { detection of similarities and differences, } \\
\text { identification of essential features, categorization. }\end{array}$ & RAM. Long-term memory. \\
\hline $\begin{array}{c}\text { Compilation of information. Building an FCM } \\
\text { situation. }\end{array}$ & $\begin{array}{l}\text { Operations to convert FCM to a form suitable for } \\
\text { decision making. Selection of evaluation criteria. }\end{array}$ & Operational thinking. Visual thinking. \\
\hline
\end{tabular}

Table 3. Decision making

\begin{tabular}{|c|c|c|}
\hline Actions & Operations & The inclusion of psychological processes \\
\hline Objective definition & Objective formation operations & Long-term and random access memory. Conceptual and image thinking \\
\hline $\begin{array}{c}\text { Determining the conditions for achieving } \\
\text { the objective }\end{array}$ & $\begin{array}{c}\text { Operations formulating conditions } \\
\text { for achieving the objective }\end{array}$ & Operational thinking. Theoretical thinking \\
\hline $\begin{array}{c}\text { Develop a solution strategy. Choosing } \\
\text { the best strategy }\end{array}$ & $\begin{array}{c}\text { Comparison of different solution } \\
\text { methods }\end{array}$ & Lonemory. Theoretical thinking \\
\hline
\end{tabular}

Copyright (C) 2020 for this paper by its authors. Use permitted under Creative Commons License Attribution 4.0 International (CC BY 4.0) 
At the first stage, it is very important to respond to alarms as quickly as possible and to find the source of the accident.

Table 3 demonstrates the next stage.

If at the first stage it is important to notice the accident, then at the second stage operator will have to evaluate the current situation. At this stage, it is extremely important to analyze the situation quickly and correctly.

Table 4 demonstrates the next stage.

Table 4. Areas of error probabilities considering the types of behavior

\begin{tabular}{|c|c|}
\hline Operator Behavior Types & Error Probability Areas \\
\hline 1. Based on experience & $P_{r}=10^{-4}-10^{-2}$ \\
\hline 2. Based on rules (instructions) & $P_{r}=10^{-3}-0.1$ \\
\hline 3. Knowledge based & $P_{r}=10^{-2}-1$ \\
\hline
\end{tabular}

Before performing actions aimed at eliminating the emergency, the operator compares various solutions to the current situation (from possible) and selects the optimal.

\section{Types of staff behavior}

For rapid assessment of personnel reliability, used primarily for screening analysis (screening) to determine dominant events, error probability domains they apply considering the types of behavior (cognitive modeling) required for each operation $[2,3]$ :

1. Skill-based actions - Automated actions. They are performed strictly according to the scenarios that are set out in the instructions (similar, for example, driving a car along a familiar route). With this type of action, errors are usually associated with a combination of various forced or temporary factors.;

2. Rule Based Actions - Actions taken in familiar situations. Based on previously worked out sequences of actions that are detailed in the instructions and / or obtained from experience or training. Actions by rules are less developed than actions based on skill, because they are performed less frequently and are more complex and often require increased conscious control. Errors in this type of action are associated with incorrect diagnosis of the situation, which leads to the use of the wrong rule or instruction;

3. Knowledge-based actions - Actions performed in emergency situations when existing rules and experience cannot be applied directly. There are no ready-made instructions for these actions, they are based on general knowledge, and they must be executed in real time. Errors in this type of actions are the result of the limited time to make decisions and perform actions, as well as insufficient or incorrect knowledge.

Table 4 presents probability domains for the described types of behavior [2, 3].

Preliminary assessments of personnel post-emergency actions (in response-response to an initial event) used in PSA are expert screening [2-5].

A logical scheme to help in deciding what type of mental activity a person's actions are shown in Fig. 1.

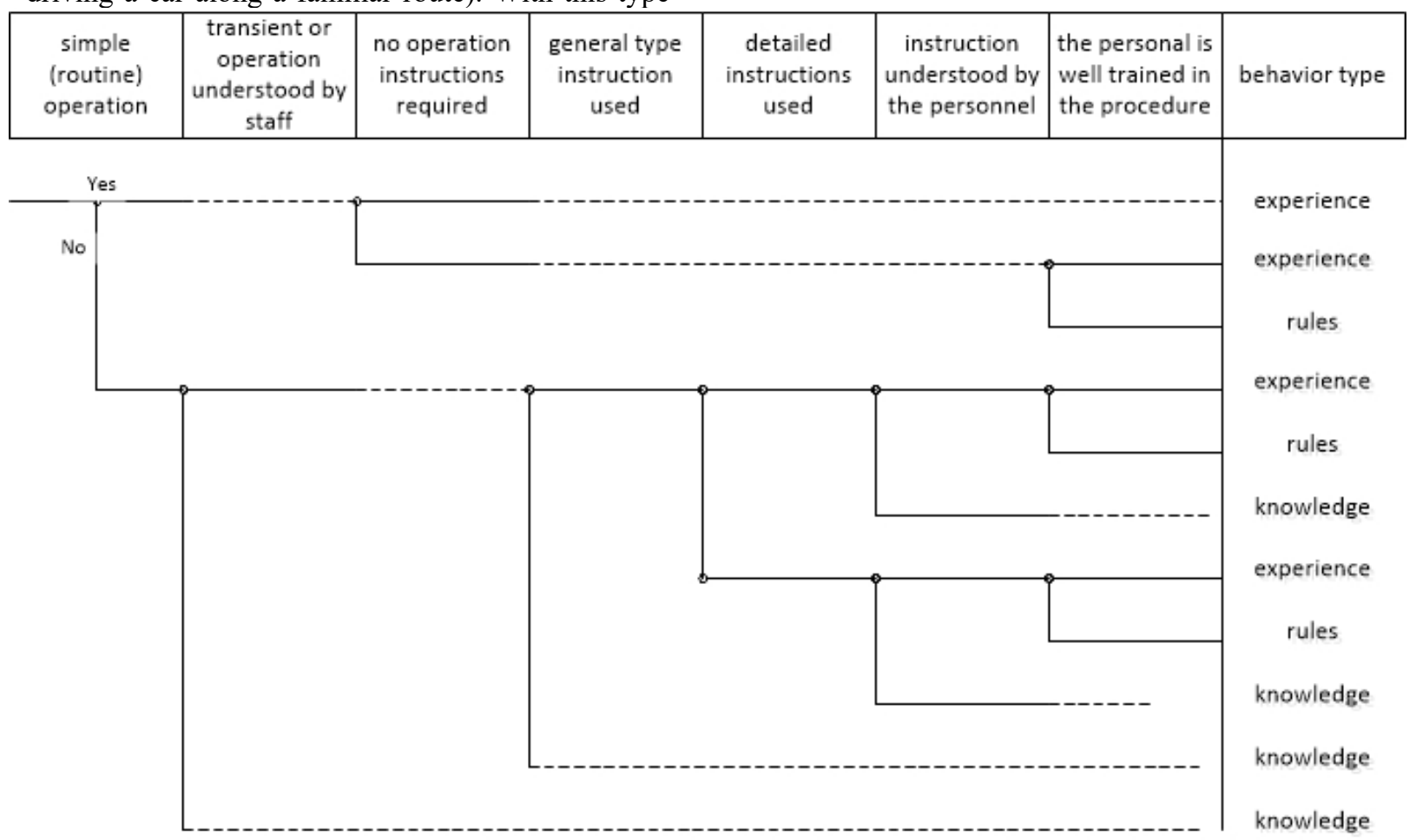

Fig. 1. A logical tree to determine the prevailing type of personnel actions in solving the problem

\section{Types (mechanism) and forms of personnel errors}

Personnel errors modeled in the PSA are usually divided into the following types related to different types of behavior:

- oversight / omission - an action leading to an unintended result due to an error during performing. This kind of error usually refers to skill-based 
actions;

- delusion is an intentionally performed action, but the intention is incorrect. This is a typical mistake in assessing a situation or in planning a response, leading to the execution of incorrect actions. This type of error refers to actions based on rules or knowledges.

Personnel errors modeled in PSA are subdivided into such forms as non-fulfillment errors and execution errors:

- Failure to comply: personnel error consisting in failure to perform one or more prescribed actions. Typically, a failure error is a failure by the operator to take the required security system into operation;

- execution error: personnel error consisting in incorrectly performing one or more actions, or performing any other action / actions instead of prescribed ones. Typically, a runtime error is either an inappropriate termination of a required security function, or an inappropriate activation of a system or initiation of a security function.

The relationship between the actions of the staff takes place if the result of a specific action depends on the previous action or actions. The probability of personnel errors in dependent activities should be higher than if they were considered independent. All alarm sequences, which include several personnel errors, are analyzed for their potential dependencies. Whenever possible, completely dependent personnel errors are redefined and modeled as a single event.

\section{The effect of stress on decision making}

The main factors that affect the behavior of personnel and the reliability of their actions are considered in a detailed analysis of personnel errors:

- instructions (the following aspects of instructions are evaluated, which are considered to be factors that influence behavior: simplicity / complexity of operations performed, number of steps, availability of a written instruction, its format (descriptive or symptom-oriented), quality of presentation, degree of detail, etc.);

- training / experience;

- human-machine interaction;

- interaction / size (composition) of the group of operators;

- information exchange;

- load;

- stress.

Not all of these factors are directly applicable to each of the analyzed personnel errors. Additional factors not included in this list may be considered.

Depending on the likelihood of the consequences of the accident and the time available to the operator for the intervention, personnel are exposed to different levels of stress. This directly affects the likelihood of correct or erroneous actions by personnel to troubleshoot in the event of an emergency. Stress can occur for a number of reasons: unpredictability of an accident, workload (its level and duration), high noise level (for example, when an alarm has triggered), conflicts during work.

Stress is not necessarily accompanied by negative reactions. The optimal level of stress will allow for better concentration, increased attention, which will favorably affect the work of the operator. At the same time, "unfavorable" (high) stress will negatively affect the work of even very experienced operators. The time limit, the difficulty of eliminating the consequences of an accident, errors, in the case of incorrect diagnosis of an accident, will only increase the level of staff stress, which will entail an increase in the likelihood of erroneous actions.

Fig. 2 shows a graph of the dependence of the operator's performance on the level of stress experienced by him [6-8].

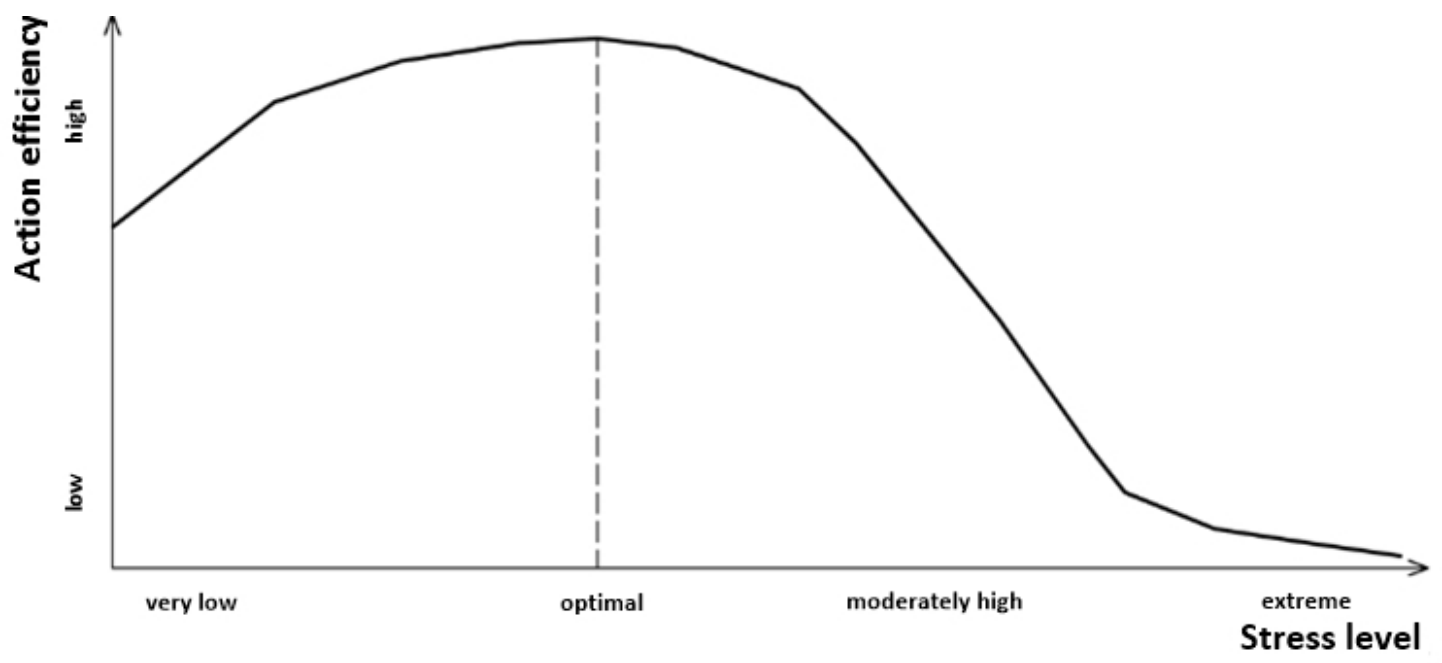

Fig. 2. The graph of the dependence of the operator's performance on the level of stress experienced by him

\section{Types of motivation for activity}

The following types of motivation for activity are distinguished [1]:
Cognitive motivation - a manifestation of interest in the content of the activity. The process of work attracts a person, the result is important for him of every task.

Conflict avoidance is the pursuit of a conflict-free 
style of behavior. They distinguish motivation for avoiding conflicts with the social environment and with their own principles.

The prestige motivation is the realization that the activity carried out is respected and gives weight to the individual. It is expressed in desire to assert oneself.

Utilitarian motivation - the possibility of obtaining good earnings or other material wealth.

Human activity is mobilized in real activity in the form of a system of motives leading to actions.

Motives are formed and rebuilt in the process of professional development of the employee and in his daily life.

There are some differenties between situational components of activity that is external, objective and internal, and mental.

External, objective components are the complexity of the task and its compliance (or inconsistency) with the conditions of execution:

- equipment and the possibility of its application for solving problems;

- deadlines (sufficient or short);

- mission statement.

Internal, mental components of activity:

- professional training;

- functional state (mood, health, fatigue, etc.) for the duration of the task.

A person who is not ready for psychophysiological qualities to work that requires high emotional stability, endurance, self-control and a strong nervous system, under the influence of poor health or conflict, is inclined to dishonestly perform the tasks assigned to him, thereby causing irreparable damage to the task and the project as a whole.

When solving habitual, everyday duties, situational and target settings may coincide in time and not be fixed in the human mind.

If decisive actions are required to solve a nonstandard problem with a shortage of time, the formation of the target setting becomes stressful. The more controversial the situational and target settings, the higher the level of stress experienced.

For example, the desire to remove the driven unit from a dangerous state and the realization that it is impossible to do this for objective, situational reasons or when the employee does not know how to do this in this situation. This is a typical situation preceding a forced shutdown of a reactor when there is not enough time or information to understand what needs to be done to prevent shutdown.

The opposite picture may also occur - the operator knows what is being done in the specific threat of block exit from the given mode, but if there is even the smallest risk, he prefers to provide work to an automatic protection system that will stop the block.

The knowledge gained as a result of long preparation and training predetermines the success of the activity and its productivity, sets such characteristics as accuracy, infallibility, speed and overall reliability of the operator's actions.

In the long term, the creation and application of systems for the operational assessment of the situation and the development of recommendations in the conditions of uncertainty implemented on the basis of studies developed in $[9,10]$.

\section{Conclusion}

Further planns:

1. To continue work on the assessment of personnel actions in the most dangerous accidents with the emission of thermal neutron sources with a low flux density.

2. To develop a methodological approach to solving the problems of assessing doses of external and internal exposure and assessing damage to the population (taking into account the age composition of the population) living around nuclear power plants during the most dangerous accidents involving the emission of thermal neutron sources with a low flux density.

3. To develop an atlas of risk metrics and a program for monitoring (control) the safety of nuclear power plants.

\section{Acknowledgment}

The reported study was funded by RFBR according to the research projects № 18-07-00225, 18-07-00909, 1807-01111, 19-07-00455, 20-04-60185.

\section{References}

[1] Abramova V.N., Belekhov V.V., Belskaya E.G. Psychological methods in working with personnel at nuclear power plants. -M.: Energoatomizdat, 1988.

[2] Haunaman G.W. and Spurgin A.J. Systematic Human Action Reliability Procedure (SHARP), EPRI NP-3583, Electric Power Research Institute, Palo Alto California, Project 2170-3, Interim report. June 1984.

[3] Per Holmgren «Enchancing Conditions for Ignalina Nuclear Power Plant in Lithuania (RBMK-Reactor Type). RELCON AB, Box 1288, S-172 25 Sundbyberg, Sweden.

[4] Consumers power company and pickard, lowe and garrick, Midland Nuclear Plant Probabilistic Risk Assessment, Irvine, C A, 1984.

[5] Peter Jacobsson end Per Holmgren. «Human Interactions Analysis V3.3», BRP (93) 6. (1993).

[6] Syngaevskaya A.A., Berberova M.A., Derevyankin A.A. Studying the effect of stress on the probability of errors by NPP personnel as part of personnel reliability analysis // CPT-2018: proceedings of the International Scientific Conference. - ProtvinoMoscow: Publishing House. IFTI, p. 282-288.

[7] M.A.Berberova, S.S.Zolotarev, «NPP risk assessments results dependence study on the composition of the population living around the NPP (on the example of Rostov and Kalinin NPP)», GraphiCon 2019 Computer Graphics and Vision. The $29^{\text {th }}$ International Conference on Computer Graphics and Vision. Conference Proceedings (2019), Bryansk, Russia, September 23-26, 2019, Vol-2485, urn:nbn:de:0074-2485-1, ISSN 16130073, DOI: 10.30987/graphicon-2019-2-285-289, 
http://ceur-ws.org/Vol-2485/paper66.pdf, p. 285289.

[8] M.A.Berberova, K.I.Chernyavskii, «Comparative assessment of the NPP risk (on the example of Rostov and Kalinin NPP). Development of risk indicators atlas for Russian NPPs», GraphiCon 2019 Computer Graphics and Vision. The $29^{\text {th }}$ International Conference on Computer Graphics and Vision. Conference Proceedings (2019), Bryansk, Russia, September 23-26, 2019, Vol-2485, urn:nbn:de:0074-2485-1, ISSN 1613-0073, DOI: 10.30987/graphicon-2019-2-290-294, http://ceurws.org/Vol-2485/paper67.pdf, p. 290-294.

[9] Osipov V.P., Chetverushkin B.N., Baluta V.I., Nechaev Yu.I. A formal apparatus for modeling and interpreting antagonistic conflicts based on an electronic training ground. KIAM Preprints M.V. Keldysh. 2018. No. 181.P. 1-28.

[10] Baluta V.I., Osipov V.P., Chetverushkin B.N., Yakovenko O.Yu. Conceptual issues of model representation of conflicts / In collection: CPT2019 International Scientific Conference of the Nizhny Novgorod State University of Architecture and Civil Engineering and the Research Center for Physical and Technical Informatics. Proceedings of the International Scientific Conference. 2019.S. 27-39.

\section{About the authors}

Berberova Maria A., PhD, docent, MIREA - Russian Technological University, E-mail: maria.berberova@gmail.com

Khakimova Aida Kh., PhD, docent, Kama Institute (Naberezhnye Chelny, Russia), ANO «Scientific and Research Center for Information in Physics and Technique» (Nizhny Novgorod, Russia), E-mail: aida khatif@mail.ru

Zolotarev Oleg V., Ph.D., Docent, ANO HE «Russian New University» (Moscow, Russia), E-mail: ol-zolot@yandex.ru 